$$
\begin{aligned}
& S H \\
& 167 \\
& 786 P_{3}
\end{aligned}
$$



SH 167

. T86 P3

Copy 1

\title{
A METHOD OF CULTIVATING RAINBOW TROUT AND OTHER SALMONOIDS
}

\author{
By Charles L. Paige
}

Paper presented before the Fourth International Fishery Congress

held at Washington, U. S. A., September 22 to 26, 1908

BULLETIN OF THE BUREAU OF FSHERIES : : : : : : VOL XXXVIII, P. 781-787

Document No. 677 : : : : : : : : : : : : : : : : : : : Issued April, 1910 


$$
c^{k}<^{10} 8^{\circ}
$$

APP 151910

98. 150

$\therefore \vdots$ 


\title{
A METHOD OF CULTIVATING RAINBOW TROUT AND OTHER SALMONOIDS.
}

\author{
$*$ \\ BY CHARLES L. PAIGE.

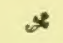 \\ CLAIMS OF THE METHOD.
}

The experiments here described were conducted on Boulder Creek, in the Shasta Mountains, in Shasta County, Cal., in water to which the rainbow trout is native, under most favorable conditions for studying the fish and its habits. The experiments were made independently, with a view to determining a method for propagating trout without stripping the fish and resorting to the process of hatching the eggs artificially.

The claims established by the results of these experiments are:

I. That the rainbow trout (Salmo irideus, and probably nearly all the genus Salmo) will readily deposit their spawn in runs or races properly arranged; that after spawning the fish may be excluded from the runs or races, to prevent egg eating and cannibalism; that the water can be regulated under control while the eggs are in process of incubation where naturally deposited by the parent fish; that a high percentage of the eggs will produce hardy fry without other care than the proper regulation of the flow of water in the race and the exclusion of such fish or animals as prey upon the eggs, embryos, or young fish.

2. That when the fry appear, as they swim from the nests of the spawning beds of the race, they may be readily diverted into nursery pools connected with the race without any handling whatever, and that they may be there cared for and fed, if necessary, more advantageously than they can be in troughs or crowded colonies.

3. That pools made ready and filled with water for some months before the fry hatch will accumulate natural food for the fry, and where they are connected with an open race of running water this food supply is continued by the natural succession of aquatic and insectiverous food that is denied to fry hatched and held under artificial methods.

4. That the fry, having more water area, more varied and natural conditions in the flow of water - such as swift water, shallows, and depths-are not forced to constant struggles; that in an adequate race with side pools they have natural foraging area and may follow their instinct of independent exploration and solitary habits. 
5. That the method proposed is superior in that it follows natural conditions governing the propagation and welfare of the fish, only eliminating and providing against the destructive forces, such as floods, drought, the tendency of trout to prey upon the eggs and young, and protection against such other fish and animals as prey upon the eggs, embryos, and young fish.

6. That the proposed method of causing the trouts (and probably under favoring circumstances, most of the salmon) to deposit their spawn in prepared runs or races, and the subsequent care of the nests and the young fish, may be more economically carried out than the artificial method of collecting eggs, impregnating them, and thereafter caring for them, as it is now practiced in most hatcheries, involving expensive plants and skilled attendants.

\section{REPORT OF EXPERIMENTS.}

In support of the foregoing claims for the advantages of the system outlined, it is manifestly impossible to submit a portable model or other more tangible evidence than the sketches and particulars herewith submitted. The facts of experiments made are briefly summarized as follows, with the aid of diagrams I, 2, and 3 :

With a series of four ponds, constructed within a few yards of Boulder Creek, in which the rainbow trout are native, water sufficient to provide a flow through the ponds was diverted thereinto by way of an open trench 300 feet in length. The ponds are about 30 by 60 feet in area and range from 2 to 6 feet in depth. Several falls over weirs aerate the water sufficiently. The embankments are walled with bowlders, laid up without masonry, and in all respects the ponds comply with the natural conditions of the stream as nearly as can be devised. The temperature of the water in the ponds ranges from $40^{\circ}$ to a maximum of $83^{\circ} \mathrm{F}$., the latter high temperature occurring several days in the month of August, I908, and lasting but a few hours in the afternoons of the warmest days. The fish suffered no ill effects from this extreme temperature, but were for the time manifestly restless and alarmed.

For two years, covering the spawning seasons of 1906 and 1907 , from 40 to Ioo adult rainbow trout were held in the ponds. These trout were taken from Boulder Creek with hook and line, readily became domesticated, all remained in good condition, and are at present among the largest of the breeding fish in the ponds.

The first season (October, I905, to April, I906), the larger of the fish spawned in beds made around the shores of the ponds, and in due time between IOo and 200 fry reached the surface. The little fish, with the exception of half a dozen, disappeared within a month. Five or six only survived.

The second year (1907), while a larger number of the parent fish spawned still fewer fry appeared, and but four of these reached the yearling stage. This 
season the fish were closely observed and it was ascertained that some of the smaller fish, apparently nonspawners, invaded the nests and with their noses dug into the gravel after the eggs. None of the fish was ever seen in the act of devouring fry, but the disappearance of the young could be accounted for in no other way than by the assumption that they were devoured by the adult fish.

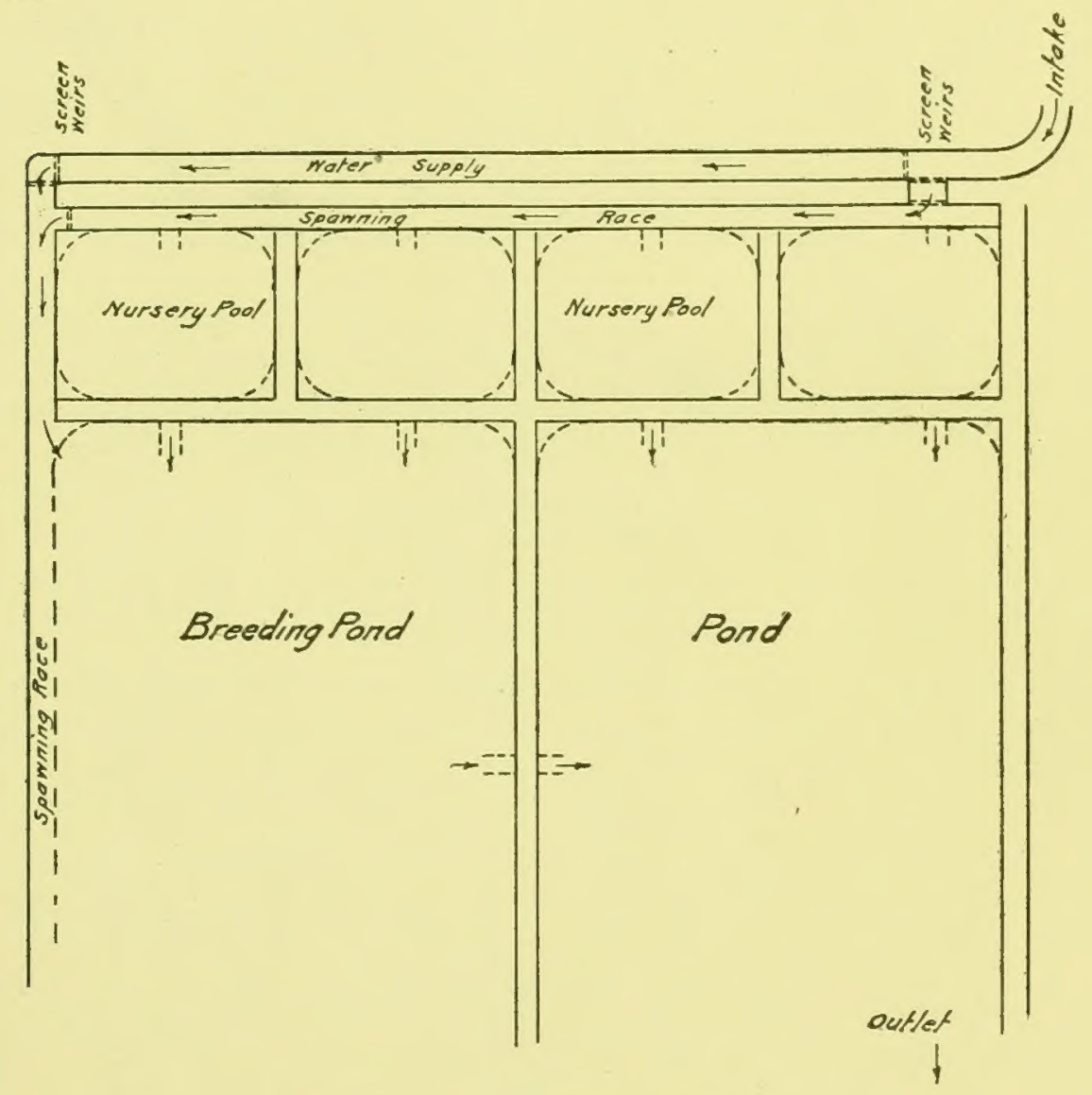

FIG. 1.-Plan of ponds and spawning race.

In September, I907, a spawning race was constructed and connected with the ponds, substantially as shown in diagram $\mathrm{I}$, and the inflow water was diverted through the race to the ponds. The race is $2 \mathrm{I} / 2$ feet wide, roo feet in length, and is paved with stones, loosely placed, and then covered partially with coarse sand and gravel. The race has a grade of approximately $\mathrm{I}$ in 20 , and is made spiral in form, owing to limited ground area. Water affording a depth of 3 to 6 inches passed through it, the gradient giving it a rapid flow. 
The fish soon accustomed themselves to the race, and at the spawning time about a dozen pairs of the larger trout conducted their spawning in it. Owing to the aggressive disposition of some of the males, the race proved to be too small for all the fish, and some of them nested in the ponds, as in previous seasons.

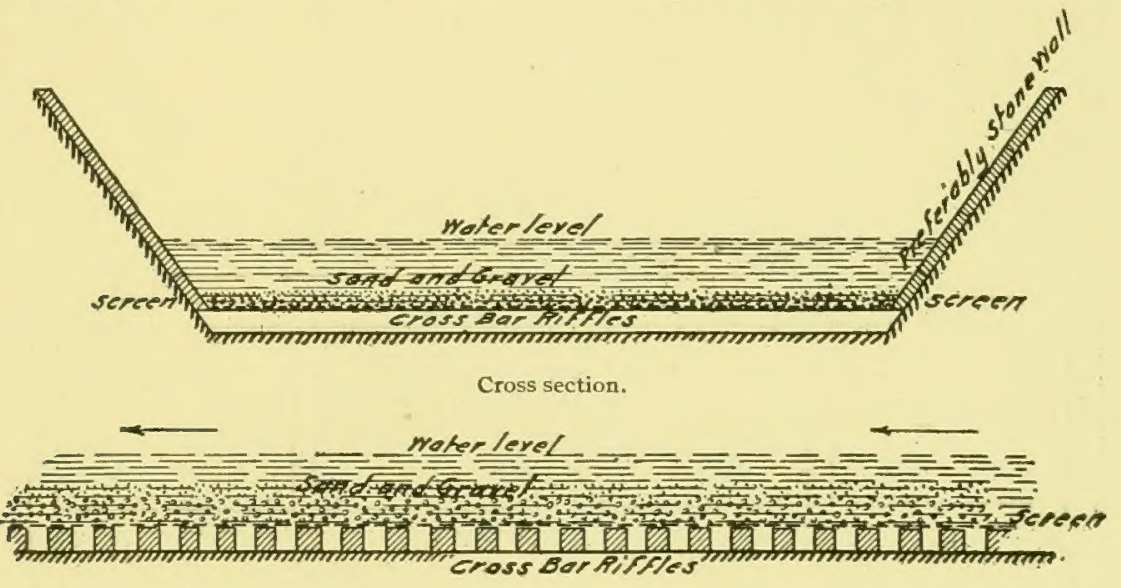

Longitudinal section.

FitG. 2,-Spawning race.

NoTE.-Screen is used to prevent the clogging of the rifles, but with properly proportioned quantities of gravel and coarse sand the screen may be omitted. The eggs and milt of the fish should sink into the riffles with the finer particles of sand, to prevent fish from devouring the eggs during the spawning period.

The race was in the open air, covered at intervals with strips of burlap laid over wire netting to afford shaded portions. The spawners showed no preference as to the shaded or the open spaces, nesting in both. In some instances they

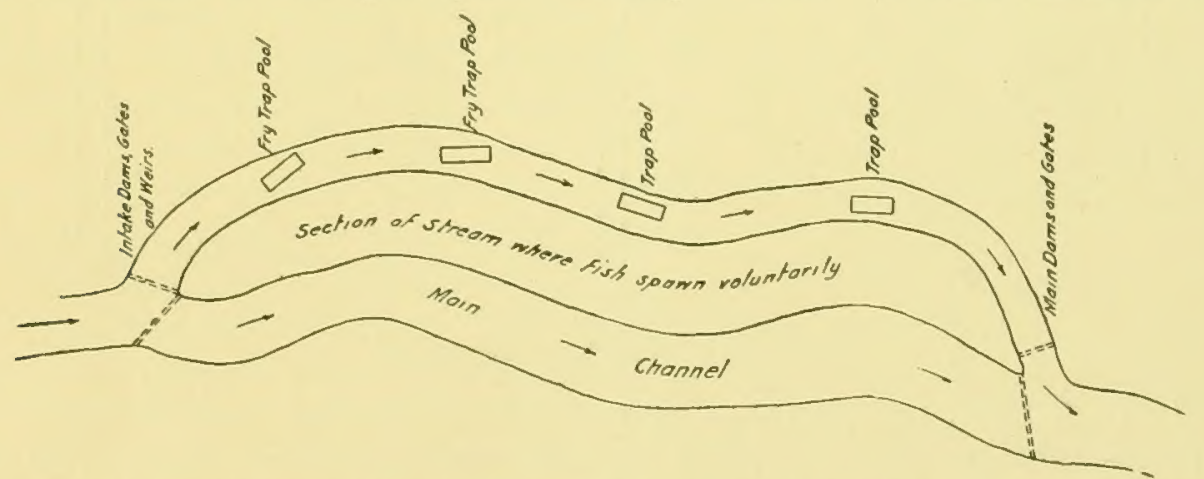

Frg. 3.- Suggested arrangement of a stream for the control of trout or salmon at the spawning season, and for the collection or rearing of the fry after the eggs have been naturally deposited and hatched. Sketch shows side channel, canal or prepared race, with flow of water regulated and controlled by dams, weirs, and gates. Under favoring conditions both channels might be available.

spawned in water too shallow to cover their backs, and in the open sunlight. Wire netting was stretched over the race to protect it from disturbance by birds and domestic animals, but it had no further attention until the fish abandoned 
their nests, about April 5. The run was then cleared of all fish, the water partly shut off, and screens placed at each end to exclude fish and destructive animals.

COMPARATIVE RESULTS.

About April 20 fry first appeared in the race, and fine screens were placed to prevent their escape into the ponds or out at the inflow. Two pools had been prepared for them and these were now connected with the race. By June I between 2,000 and 3,000 fry had hatched in the race, and these were about equally distributed in the race and the two pools. At the present writing (August Io, I 908) less than a dozen of the fry have died from any cause, and several of these perished by being caught in the screens. The fry now average nearly three months of age and are in thrifty condition, with no evidence of weakness among them.

Not above twelve pairs of the fish spawned in the race, and several of these were small females which were seen upon the nests but a few times, while the larger fish occupied the nests at intervals during six to eight weeks. It is to be considered that trout deposit but few eggs at a time, and this would appear to be a strong argument against the stripping process.

The fry appeared in the race, by careful count and removal, as follows:

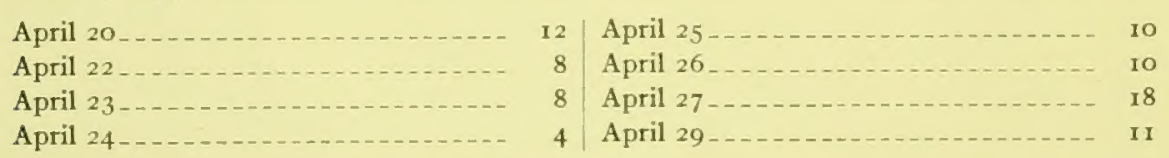

Thereafter, until late in June, from 20 to 50 fry appeared daily, and the number then decreased until all had hatched. This may or may not be approximately the ratio in which the eggs were deposited, but it must be of value as proof that they are deposited but few at a time, and covering considerable time.

More than half of the spawners were kept out of the race by the pugnacious males, or elected to spawn in the ponds. Some of these were the larger fish and continued spawning throughout the season. Smaller fish, spawn-eaters, were continuously raiding the nests in the shallows of the ponds. Only about 20 fry appeared during the hatching season, and a dozen of these were saved by being dipped out with a net and placed in the fry pools. None of the others survived.

In conclusion, I desire to submit that these experiments, entailing much labor and time, and observations made under very favorable conditions and carefully recorded, have convinced me that it is not practicable to propagate trout in limited areas of inclosed water, without provision for the protection of both the spawning beds and embryos, and also the segregation of the fry until they are at least six months of age.

I do not believe a simpler, more practicable, or economical method can be devised to meet these requirements than the provision of adequate runs or races, together with nursery pools for the fry, substantially as outlined in this paper. 
LIBRARY OF CONGRESS

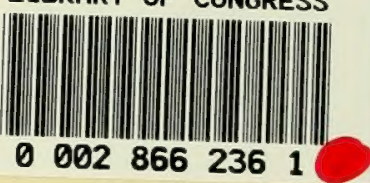

